Interpreting unproblematic high achievement in mathematics: towards theoretical reflexivity

David Pomeroy

Faculty of Education, University of Cambridge, UK and Faculty of Education, Victoria University of Wellington, New Zealand

Email: david.pomeroy@vuw.ac.nz 


\section{Interpreting unproblematic high achievement in mathematics: towards theoretical reflexivity}

This article contributes to the long-running discussion about the gendering of mathematics learning by exploring the social biographies of six exceptionally high attaining mathematics students, four women and two men. In contrast to some prior studies, these students appeared to feel no need to downplay being 'good at maths' in order to maintain social credibility with their socially privileged peers. I attempt to make sense of their stories from two theoretical standpoints: 1) a post-structuralist approach that emphasises discourses that position mathematics as masculine, and 2) an approach, based on Bourdieu, that asks how mathematics is valued in different school and peer group settings. I show how, as I worked with the data, my emphasis moved from the former to the latter, and suggest that research in gender and education has much to gain from theoretical reflexivity alongside personal and methodological reflexivity.

Keywords: gender; mathematics; post-structuralism; Pierre Bourdieu; social class; high achievers

\section{Introduction}

In a recent discussion of the abject versus privileged positioning of students with 'geek' or 'boffin'1 identities, Mendick and Francis (2012) explored the way in which "membership of a community of practice" (p. 19) can mediate the way the 'geek'/'boffin' label is experienced. The authors' hope was 'to have incepted a discussion on the ways in which aspects of social structure impact the likelihood and experience of being categorised as a boffin/geek" (p. 21). My hope is to continue this discussion, particularly in relation to the way in which social class impacts the experience of being categorised as 'boffin/geek'. Whilst there is an important distinction between such labels being conferred by others (often pejoratively) and owned (more positively), I will argue that what also matters is the socially mediated force of the label itself, whether conferred or owned. 
This article has two primary aims, one empirical and one theoretical. The empirical aim is to document and explore how a small group of exceptionally highattaining mathematics students came to identify as 'good at maths' with little apparent “identity work" (Mendick 2006, p. 23) required. The analysis is based on biographical interviews with research students of diverse nationalities, all studying at an elite British university. The theoretical aim is to explore the potential of combining post-structural gender theory and Pierre Bourdieu's (1984) ideas about how things are valued in different fields. In recent years, analysis of the gendering of mathematics learning has been framed primarily in terms of the ways students take up and are taken up by powerful social stories or 'discourses' about what it means to be a girl, a boy, and a mathematician (e.g., Epstein et al. 2010; Palmer 2009; Smith 2010).

This article begins with an explanation of how I decided which theories to use in my data interpretation, drawing on Andrew Sayer's (2000) development of critical realism for the social sciences. I then present a review of two strands of literature. Firstly, I introduce discourse analyses of gender inequalities in mathematics education, in other words, analyses that rely heavily on discourses or 'cultural stories' about girls, boys, mathematics and mathematicians. Secondly, I review literature that has drawn on the work of Bourdieu (1984) to engage with the ways in which a student's social class and gender make it easier or harder for them to do well at school. Next, I introduce the 'mathematical biographies' of my interview participants, and the difficulty of reconciling their positive mathematical identities with unflattering and gendered discourses about what it means to be 'good at maths'. I then discuss the potential complementarity of post-structural theory and Bourdieu's social theory in making sense of how students come to see themselves as learners, and suggest theoretical reflexivity as a way to think about how we construct meaningful narratives from messy data. 


\section{Complementary/rival theories: a critical realist approach}

Critical realism (Bhaskar 1975) provides a helpful framework for engaging with the 'meta-theoretical' questions such as, What theoretical framework(s) shall we use?, How do we make sense of our data? Realism's basic claim is that the world exists independently of our consciousness of it, implying that our scholarly conversations are about something, they have a referent (Sayer 2000). Critical realism acknowledges the fallible and contested nature of our knowledge of the social world. So within this framework there are real reasons for gender inequalities - complex, context-dependent reasons, but reasons that are not just made up by researchers - and we can describe these reason in different ways. Different scholarly conversations about gender and mathematics education are in a sense 'about the same thing' even if they are generated in different academic communities or schools of thought (Sayer 2000). Some scholarly discourses may be more 'true' to what they study than others, and different scholarly discourses may be appropriate depending on details such as the national or social context of the study. Hence the choice of the most appropriate theoretical framework for a study may depend on the nature of the data, and need to be revised.

In recent years, scholars from a variety of disciplines and theoretical approaches have gone beyond statistical descriptions of gender inequalities and sought explanations. For example, experimental social psychologists working with notions of prejudice and stereotyping have proposed that "when women perform math, unlike men, they risk being judged by the negative stereotype that women have weaker math ability" (Spencer et al. 1999, p. 4). Significant advances in scholarship about gender and mathematics have also been made using the post-structural concept of discourses, or powerful ideas about what it means to be a girl, a boy, or a mathematician (Mendick 2006; Walkerdine 1998). Whilst not applied specifically to mathematics, sociologists of education have used Boudieu's concepts of habitus and field to make sense of the 
tensions generated when students' (often 'classed' or 'raced') performances of gender have different values at home, amongst peers, and in the classroom (Francis et al. 2010; Ingram 2011; Reay 2002). I do not wish to trivialise, nor will I attempt to fully describe, the profound differences between the assumptions underpinning experimental psychology, post-structural feminism, and Bourdieusian sociology. However, it is hard to escape the conclusion that the three research programmes alluded to in this paragraph are all researching a similar phenomenon. It is impossible to describe that phenomenon in language that does not privilege one theoretical approach, but a simple description would be that they are all interested in gendered learning processes. Whilst at a theoretical level it could be argued that there are fundamental incompatibilities between these theories as theories, I hope to show that they can be mutually informative when considered theories as methods.

\section{Discourses about gender and mathematics}

A rich vein of research about gender and mathematics (e.g. Cann 2009; de Freitas 2008; Palmer 2009) theoretically positions itself within the post-structural feminist tradition, drawing on the gender theory of Judith Butler (1990), Bronwyn Davies (2002) and others, and on Michel Foucault's (1972) work on discourses. Major contributions to this body of work have been made by Valerie Walkerdine and colleagues (Walkerdine 1998), and more recently by Heather Mendick and colleagues (Epstein et al. 2010; Mendick 2006). A central feature of the analytical work of these authors is the pivotal role of discourses about gender and mathematics in the generation of educational inequalities. For example, Walkerdine (1998) argued that many teachers subscribed to the cultural myth or discourse that boys are active and girls are passive, and that as a result of this teachers interpreted students' achievement in gendered ways; high achieving girls were 'hard working' whereas high achieving boys had 'flair'. 
Using discourse as an interpretative tool makes certain kinds of analysis possible. Discourses about what it means to be a mathematician or 'good at maths' function to join ideas together, like attaching the idea of 'the mathematician' to personal traits such as poor social skills, being "obsessed with the irrelevant" (Mendick 2006, p. 62), or white, middle-class masculinity (Epstein et al. 2010). A language of discourse also allows researchers to describe and critique the way opposing terms, such as active/passive, reason/emotion, and natural talent/hard work, come to take on gendered meanings (Mendick 2006). Such analysis is all the more compelling when it is underpinned by an investigation of the historical and cultural origins of discourses. Notably, Walkerdine (1998, p. 35) argued that during the 'Enlightenment' a gendered discourse around reason gained widespread currency:

"Rationality was taken to be a kind of rebirth of the thinking self, without the intervention of a woman. The rational self was a profoundly masculine one from which woman was excluded, her powers not only inferior but also subservient" (Walkerdine 1998, p. 34).

Walkerdine's work was ground-breaking in an era when female underachievement in school mathematics was widely seen as a predictable consequence of 'natural' gender differences in the capacity to reason. She argued of such discourses that "they are not false statements that can easily be swept aside to tell the truth about women: rather they claim the truth for themselves" (Walkerdine 1998, p. 165).

Mendick, Epstein, and Moreau (Epstein et al. 2010; Mendick 2006; Moreau et al. 2010) further developed this line of thought in their analysis of discourses about mathematics in popular culture. Drawing on direct analysis of films and books as well as interviews with students, they argued that popular cultural discourses often depict mathematicians as "white, heterosexual, middle-class men" (Moreau et al. 2010, p. 25) who are "isolated, obsessed, possibly autistic but certainly socially inept" (Epstein et al. 
2010, p. 52). They argued that whilst some students were able to subvert the 'geeky' connotations that this discourse attaches to mathematics, using it to generate a more positive 'geek capital', students were unable to find alternative discursive resources for the construction of their mathematical identities. It should be acknowledged that Mendick and colleagues identified some more positive images of mathematicians, such as the brainy, heterosexual male who saves the day with his intelligence (Epstein et al. 2010). Cathy Smith (2010) also described how English Further Mathematics ${ }^{2}$ students viewed mathematics as a dependable path to the futures they desired, so it would be remiss to portray mathematics' discursive associations as exclusively negative. However, I think it is fair to say that the majority of the English language literature on cultural representations of mathematics and mathematicians are in the 'geek/boffin' vein and are overwhelmingly negative.

Other scholars have described practices that they suggest may challenge gendered discourses about mathematics. For example, Elizabeth De Freitas (2008, p. 281) discusses the way in which written self-narratives can be used to "provisionally trouble or unfix the binary between the feminine and mathematics". Anna Palmer (2009) worked with early childhood trainee teachers in an unconventional course which challenged the students to reflect on and deconstruct their often gendered assumptions of what it means to be a 'maths person'. A significant function of the work alluded to here has been to show that discourses about gender and mathematics as not merely descriptive but also powerful, a position that leads to questions about strategies students use to resist the power of discourses. The next section explores a second framework for understanding educational inequality, Bourdieu's (1984) theoretical concepts of habitus, field, and capital. 


\section{Gender, mathematics, and Pierre Bourdieu}

Bourdieu's sociological work has proved very fruitful as a lens for interpreting data on what makes it easier or harder for students to do well at school. That set of dispositions towards certain ways of speaking, acting, and interpreting our world that Bourdieu called habitus influences our relationships with elements of the social and academic fields that we inhabit (Bourdieu 1984). For the purposes of the current analysis, I use the language of academic and social fields rather than simply classrooms and peer groups, to emphasise the different social hierarchies and value systems of classrooms and peer groups. The academic field of the classroom is not just the physical space, but rather the system of academic rewards and credentials that accrue to students in return for certain types of learning behaviour. Similarly, a social field of peers is defined not just by its membership, but also by the types of behaviour that are valued by its members. Students must simultaneously negotiate the social fields of their families and peers, and the educational field of the school. Each of these fields will have a unique, hierarchical structure, and the nature of the field will determine what different products are worth, that is, the extent to which they count as capital (Bourdieu 1984; 1991). For example, gender-normative social behaviour such as flirting may count as capital within students' peer groups, but not contribute to their attainment of valued academic credentials.

The above conceptual framework facilitates a process of data interpretation and narration in which explicit attention is paid to the congruity and conflict between the demands of educational and social fields (or between different social fields). Such a framework has been used to interpret the experiences of working-class students in schools (Ingram 2011; Reay 2002) and elite universities (Reay et al. 2009). Diane Reay argues that behaviours that count as valued capital in educational fields can be liabilities in many working-class social fields. For example Shaun, a white, working-class boy, 
must balance the need to be seen as tough and defiant by his peers with gentler sentiments towards pleasing his teacher and his mother (Reay 2002; 2015). This tension contrasts with a seamlessness that can exist between what educated, middle-class parents inculcate at home and the implicit expectations of the school (Bernstein 2000; Reay 1998). Nicola Ingram (2011), in her study of the identities of academically successful working-class boys in Belfast, explored in considerable depth the way the sometimes conflicting forces of home and educational fields moulded, 'split', and 'tugged' the habitus, often engendering difficult emotions. Ingram (2009) emphasises that the boys' performances of academic success are shaped by home influences on their habitus, and by the institutional habitus of the schools they attend. Of particular relevance to the argument I am developing is Ingram's contention that what counted as an acceptably masculine, working-class performance of academic success was contingent on various aspects of students' social fields, including the culture of the school and students' peer groups.

Feminist scholars working with Bourdieu have done much to extend his work, which is primarily focused on social class, into gender analysis, and intersections of social class, gender, and in some cases ethnicity (Ingram 2009; Reay 2006; Skeggs 2004). Beverley Skeggs (2004), for example, has argued that many workplace fields are hierarchically structured in favour of men. In particular, traits discursively positioned as masculine, such as assertiveness, are rewarded in men and pathologised in women, whereas traits discursively constituted as feminine, such as caring, are rewarded in men and taken for granted in women. In making this argument, Skeggs uses gender as a category of analysis within a Bourdieusian framework and shows how gender can function to deny women access to certain 'off-limits' areas of a field. Furthermore, as Reay (2002) and Ingram (2011) have argued, the social fields that their students 
inhabited rewarded very different performances of academic success from boys and girls. Francis and colleagues note how girls' 'hyperfeminine' behaviour in mathematics can be read as an attempt to demonstrate a feminine capital that is threatened by displays of mathematical intelligence, with its connotations of socially inept masculinity (Francis et al. 2010). Scholarship such as this feeds into Mendick and Francis' (2012) discussion of how social structures mediate students' identification or dis-identification with mathematics and mathematicians.

In the last two decades there have been pockets of research that apply Bourdieu's ideas specifically to mathematics education (Cooper and Dunne 2000; Gates and Jorgensen 2009; Noyes 2006; Zevenbergen 2005). Cooper and Dunne (2000) argued that middle-class children tended to view school mathematics as being more abstracted from everyday knowledge, putting middle-class children at an advantage when it came to determining what test questions were implicitly requiring of them. Zevenbergen (2005) used the idea of habitus to explore the way students' experiences of high and low set classes affected their perceptions of themselves as mathematics learners. Teachers' gendered interpretations of students' feminine 'hard work' and masculine 'brilliance' (Walkerdine 1998), or textbooks' implicit portrayal of 'the mathematician' as male (Dowling 1996) all suggest an educational field that demands different performances of girls and boys. The gendering of what counts as capital in the field of mathematics education is in itself a reason to explore further the potential of Bourdieu's sociology in the work of interpreting data in a study of students' mathematics education. The discussion now turns to the details of the current study, before returning to questions of analysis and interpretation. 


\section{Understanding successful mathematics students and their peer groups}

\section{The study}

In light of post-structural literature that emphasises the difficulty of identifying positively as 'good at maths', I set out to develop some case studies of students who had defied the odds and developed positive identities as highly capable mathematicians. Given that much of the existing literature in this area draws on the experiences of British students, I approached a small but highly international group of masters and doctoral students, ranging in age from mid-twenties to mid-thirties, to take part in interviews (see Table 1). In order to incorporate the views of students with a range of current disciplinary identities (not just mathematicians), I interviewed students with specialisms across the natural and social sciences, and humanities. In this article I draw on interviews with six students who self-identified as 'good at maths' and had achieved very good to outstanding results in school mathematics. The study was small in scale, and the participants were not selected with the intention of being 'representative' of any particular group. The cultural diversity of the participants should be interpreted in the context of an increasingly global education market (Brooks and Waters 2011). All participants possessed the cultural competencies required to successfully navigate their way into an internationally prestigious university, so it could be argued that they had more in common culturally than their national origins might suggest. Given that there were only one or two students of any one national origin, it was not possible to infer reliably from their biographies what discourses about gender and mathematics were circulating in their home nations when they were school students.

[INSERT TABLE 1 ABOUT HERE] 
There were three individual and two pair interviews, semi-structured (Creswell 2007), ranging from 25 minutes to over an hour in length. During the interviews, we discussed:

- students' experiences of primary and secondary schooling, in relation to mathematics and other subjects, including students' enjoyment of and attainment in mathematics;

- participants' perceptions of mathematics and mathematicians, using an array of prompts including photographic portraits to scaffold discussion of what it means to be (or not be) 'good at maths'; and

- the social groups in students' schools, including which social groups the participants were and were not part of, and the academic achievement of members of each of these groups.

The interviews included a variety of questions to elicit the way students felt about their mathematical attainment, such as 'when you got a high mark in a test, who would you tell?' The interviews ended with a brief discussion about participants' families, including their parents' occupations and education levels. I used the software package NVivo to keep track of emerging themes across interviews. Some of the themes were:

- participants' descriptions of the social groups in their schools (for example, 'geeks', 'jocks', and 'teenage mums');

- characteristics associated with mathematics (for example, intelligence, and lack of sporting prowess); and

- associations between gender and mathematics.

In the remainder of the article I focus on how these students construed their own 'mathematical biographies', and the insights brought to the process of data 
interpretation by post-structural gender theory (Results and Discussion I) and Bourdieu's social theory (Results and Discussion II).

\section{Results and analysis I: using discourse theory}

The initial analysis yielded a high level of consistency across participants about how mathematics was perceived while they were at school, a consistency all the more significant given the diversity of the cultural settings in which they went to school. The 'image of the mathematician' was consistent not only between cases, but consistent with the work of Walkerdine and Mendick.

\section{Participants' perceptions of mathematics}

For example, when asked to describe someone whom he assumed (but didn't know) to be very good at maths, Peter, a lawyer and master of law student from Australia, described a colleague's physical appearance and social manner as follows: “even as a glasses wearer [myself] it's a particular type of glasses [that he wears], it's not kind of like, they're not fashionable glasses ... they're practical glasses, practical haircut, doesn't dress for fashion, dresses for practicality, you know, perfectly clean and socially acceptable, but just very practical.”

Peter went on to say that "there's always a point to the conversation, ... he'll come and talk to you but there's a point to the conversation, not just chit chat, very focussed and efficient."

Connie, a social sciences doctoral student from Latin America, described a female 'geek' as a "fat girl wearing glasses", and most participants also mentioned, without prompting, that mathematics was a "boy subject".

For Peter, mathematics was "a discipline which produces black and white answers that, you know, we follow it through logically from these premises and we get to these conclusions". These comments portray mathematics as objective, cold, and antithetical 
to emotion and intuition, a portrayal that Mendick (2006) documented and argued for the need to challenge. Several participants described mathematical ability as natural and unchanging; for Peter, "it just kind of came easy to me", and Paula, a social sciences doctoral student and former mathematics educator from Latin America, explained "I like math, I don't know, I think it's something that is inside me”. Lizzie, an Irish biological sciences doctoral student, described other students who "aren't mathematically minded", commenting that mathematics "doesn't come naturally to everyone". These and other comments are consistent with previous literature which argues that mathematical ability is often seen as natural and fixed (Bibby 2002; Mendick 2006). My participants' stories revealed the same old discourses at play, but alongside high achievement and feelings of pride, confidence, and satisfaction in being 'good at maths'.

As discussed earlier, studies using a discourse framework have made significant progress in understanding gender inequalities in how students experience learning mathematics, in their choices (not) to continue with mathematics once it is optional, and in the results they attain (Cann 2009; de Freitas 2008; Epstein et al. 2010; Mendick 2006; Mendick and Francis 2012; Solomon et al. 2011). Initially I attempted to use post-structural discourse analysis to interpret my data, but whilst there was a consistency of sorts with previous studies, this consistency could not explain the very positive mathematical identities of the six participants (four of them women) discussed in this article. I could not find evidence of the use of discourses of Enlightenment Rationality or popular culture in my female or male participants paths to identifying as 'good at maths'. Nor, for the most part, did they show evidence of strategies of resistance and subversion of these discourses, by distancing themselves from undesirable images or re-claiming 'geek capital' (Mendick and Francis 2012). Setting 
the interviews against the backdrop of prior research on gender and mathematics, what stood out was the absence of engagement with discourses about gender and mathematics. This absence seems especially noteworthy given that many of my questions aimed to elicit the way students used discourses as resources in their mathematical identity formation.

\section{Results and analysis II: using Bourdieu}

What proved most illuminating in terms of understanding students' mathematical success were the sections of the interviews in which we discussed the social groupings and hierarchies that participants recalled from their school days. I had planned these questions in order to promote discussion that revealed discourses about how various personal qualities, such as social awkwardness, might be associated with mathematics. However, the ensuing discussion also provided information about the students' peer groups and other social groups at their schools. In every case there was a mechanism by which working-class students were excluded from the participants' peer groups.

\section{Peter (Australia)}

Peter, from Australia, identified with a group he called the 'squares', a highachieving group of mainly middle-class boys. The boys Peter called the 'jocks' had high levels of popularity, mainly derived from their performance in sports. The 'jocks' also displayed hetero-normative sexualised behaviour, 'peacocking' (showing off) in front of the girls. Some of the 'jocks' were reasonably high achievers, but Peter explained that those who got good results would "keep this pretty close to their chest". The jocks, whilst potentially achieving a measure of academic success, needed to downplay this success in order to maintain credibility within their macho peer groups, rather like the 
high-achieving and popular students described by Francis et. al. (2010). In contrast, Peter described his peers as simultaneously "mates" and "academic rivals", suggesting that educational success was highly valued within this particular social field. Peter said of his 'squares' group that they were sometimes referred to as 'nerds', explaining "we probably weren't happy about the label but it wasn't anything we cared about too much and we certainly weren't bullied or anything like that".

\section{Connie and Paula (Latin America)}

Connie and Paula described the playful way their friends would tease them when they got top marks in a mathematics test. Even though they would be called "nerds", the way they describe the gentle ribbing they received conveys affection and admiration from their peers. When I asked them how they felt on receiving these marks, the reply was simple: "I would feel good". Connie was an asset to her friends, all of whom achieved significantly lower grades in mathematics than her. She would help them prepare to re-sit mathematics exams that they had initially failed, during their holidays. This gave her a powerful and valued position within her peer group.

Similarly, Paula was a considerable resource for the long-term friends that formed her stable primary school cohort, because of her ability to explain mathematics to them in a way that they understood. She was called upon regularly by her teacher to stand at the front of the classroom and explain concepts that he couldn't get across to the students. She claimed not to feel embarrassed or shamed by this - on the contrary she felt that she gained the esteem of her classmates for her understanding of mathematics and her skill in explaining it. Her claim to enjoy this, as much as it surprised me, gained credibility when she contrasted it with her experience at a new school where she was unknown by peers in her large secondary class. Here the teacher, who had moved from her old school at a similar time, was about to call on her to 
explain a concept to the class, and she warned him strongly not to do this. The field had changed, she was in a new group of peers on whose approval she could not rely, and the thought of being positioned in a teacher role terrified her. This contrast in experiences of a superficially similar situation cannot be explained by a difference in discourses about gender and mathematics. Paula herself explained the difference in terms of the change in peer group. When I asked whether anyone responded negatively to Paula taking an active and visible teaching role in her primary mathematics class she responded "no, I think that, because my class were students that were with me since we were two years old you know, so we were friends, really friends, so, you know, we didn't have this problem."

\section{Amanda (China)}

Amanda, a humanities doctoral student from a large city in China, attended a public primary school and then boarded at a selective secondary boarding and day school that was "quite famous" and charged a "relatively high fee" although it was not technically private. It had small classes, and Amanda thought it had a better reputation than a lot of the private schools. Amanda took the university entrance examination for humanities, studied history in China as an undergraduate, and has continued her studies in humanities at postgraduate level at two prestigious British universities.

Amanda achieved highly in primary school across all subjects; she was an only child and her parents were very supportive of her education. At secondary level she specialised in humanities but continued with mathematics, which was compulsory throughout school. Amanda "always attached very, very great importance to math, because it's one of the subjects of the national college entrance examination" and worked "very, very hard" at mathematics. She "did math pretty well" and was at different times the mathematics subject representative at her school and in mathematics 
competitions that were reserved for the top few students in each class. She voluntarily took after-school mathematics classes, and, on her father's advice, kept a notebook of mathematics problems she found especially challenging. As these events emerged I began to assume that Amanda must have enjoyed mathematics, but when I asked her she claimed that she didn't. Whereas Paula's attachment to mathematics came across as an almost childlike fascination, Amanda was being very strategic, doing what was necessary to get ahead in an environment of intense academic competition. Like Smith's (2010) Further Mathematics students, she saw doing well in mathematics as part of a biographical project, however, she did not seem to have the same need to enjoy the subject. Her school overtly fostered academic competition, sometimes handing out tests publicly from lowest to highest grade.

In secondary school Amanda's friends were a close-knit group of girls who boarded at the school. They were high academic achievers who were also active in leadership roles and extra-curricular cultural activities. When I asked her what they did in their spare time, she was bemused; aside from going home on the weekends, school was life. Other social groups at Amanda's school included day-girls who liked fashion and shopping, socialised outside of school, and didn't achieve so well academically as Amanda's friends. However, Amanda didn't perceive that there was a necessary tension between high academic achievement and having an active social life, and her peer group seemed to achieve both to some extent. Perhaps more than any other participant, Amanda went to a school in which academic achievement carried very high value in the academic and social fields. Furthermore, mathematical achievement seemed to be particularly highly valued socially. Mathematics and English were the subjects that "get the most respect" from her friends, especially mathematics, because it was so strategic in terms of university entrance and because it was viewed as a very difficult subject, a 
real test of intelligence. Bibby's (2002) English primary teacher participants also viewed mathematics as a difficult test of intelligence, but for many of them it yielded shame rather than respect because they identified as mathematical failures.

\section{Participants' peer groups}

It is worth pausing here to examine more carefully the characteristics of the participants' peer groups, and how these differed from other social groups within the participant's schools. I have said that high achievement in mathematics was valued in these groups; this does not mean that it was normal. The participants were all notably high achievers, even within their peer groups. This within-group difference is exemplified by Paula and Connie spending significant amounts of time helping their lower-attaining friends with mathematics. Thus, the participants were not swept along by a tide of normalised high achievement; rather, their development of high achievement was not impeded by a fear of social stigmatisation.

A second and most likely related characteristic of the participants' peer groups was relative social privilege; five of the six interviewees attended selective, fee-paying schools for at least part of their schooling. In these cases there was simply no opportunity for the students to interact with working-class peers. Yet even in the cases where participants attended comprehensive, socially mixed schools, the peer groups tended to be socially homogenous. Lizzie talked of a strong dis-identification with a group of girls whom she called "the teenage mums", whom she said "didn't go on to have a future". Her description of this group was an educational and aesthetic pathology. They lived in "more deprived areas" than she did, their families did not value education like hers did, and their tastes in clothing and music had echoes of the 'excess' that Skeggs (2004) argues marks white, working-class women. Peter's "wogs”, typically sons of Italian immigrant market gardeners, and Chris' "bad boys in the lower 
sets" were all marked in various ways as working-class and were excluded from the participants' social networks.

\section{Interpreting peer group effects}

It is tempting to infer, as several of the participants did, that these working-class 'others' simply did not value high achievement, in mathematics or any other subject. Lizzie claimed that the 'teenage mums' at her school "were low achievers and didn't really care too much about school." However, some sociologists have argued that this middle-class caricature of the working-classes renders invisible the high educational aspirations of many working-class students and their families, and that the reality is much more complex than this. For example, Reay (2004) argues that working-class relationships to education are better characterised by tension and difficult identity work than by simple indifference, and Val Gillies (2006) explores the ways in which working-class mothers make heavy emotional investments in their children's schooling. So perhaps what made my participants' peer groups different was that, in these privileged social fields, high achievement required no balancing act. They were able to identify positively as 'good at maths' because they did not need to downplay, disguise, or compensate for this aspect of their behaviour.

The dominance in the participants' narratives of social groups within their schools suggested that a Bourdiesuian approach might be constructive in making sense of my data. Within such an approach, participating actively in mathematics class, getting good results in mathematics tests, helping other students with mathematics, and other visible mathematical behaviours are all potentially valued capital. Students in the mathematics classroom are in an educational field in which actively engaging with mathematics counts as capital, and simultaneously in a social field of peers. Whether or not engaging positively with mathematics counts as valued capital in this social field 
depends on the structure of that field (Bourdieu 1991). In more concrete terms, I interpreted the structure of the social field to be the types of social responses that students experienced when acting mathematically. Many of these I have already described - playful ribbing, outright admiration, respect, and gratefulness. The emotions associated with these responses - pride, satisfaction, feeling good, feeling valued - give a sense of the structure of the students' social fields in terms of their success in mathematics. This stands in contrast to both lower-attaining students who are put off engaging with mathematics because of its discursive associations (Mendick 2006), and those who achieve well but have to downplay or compensate for their high achievement (Francis et al. 2010).

\section{Discourses, social class, and unproblematic high achievement}

Empirically, this study has attempted to contribute to existing research on gendered experiences of learning mathematics by exploring the 'mathematical biographies' of six exceptionally successful students who felt at ease self-identifying as 'good at maths'. Previous studies have illuminated the struggles and difficult identity work that so often characterise students' orientations to school mathematics. These studies have shown, amongst other things, that many students are unable to see themselves as 'good at maths', whilst others actively resist and subvert discourses that position mathematics as incompatible with femininity and sociality. Such studies have already noted the relationship between students' success in maintaining positive mathematical identities and the social environments students inhabit, for example by arguing that university students require less identity work in order to see themselves as 'good at maths'. The current study suggests that in social environments where mathematical success is accorded high enough admiration and respect, a different and less taxing form of identity work may be required, and the discourses may have diminished power over the 
students, despite students' awareness that the discourses exist.

In the case of the students whose stories form the basis of this study, such social environments were strongly associated with socio-economic privilege. However, given the study's small sample size, the relationship between unproblematic high achievement and social privilege should be treated as a tentative finding. Recruiting graduate students at an elite university had the advantage of providing an unusual concentration of high achievers with positive mathematical identities. However, a corresponding disadvantage was that all participants had high levels of cultural capital, in global terms and relative to their home societies. Therefore, my ability to compare these students with those in prior studies is limited to Anglophone countries, especially England. For example, it is plausible that Chinese or Latin American students require less identity work to engage positively with mathematics than English students regardless of social privilege. I cannot infer whether or not this is the case based on my interviews, and similar studies in a wider range of national and cultural settings (or investigation of nonAnglophone literature) could prove fruitful in extending this discussion. Prior to conducting further research, a comprehensive cross-disciplinary review of literature, including post-structural and sociological studies as well as the psychological literature on gender stereotype threat in mathematics education, could prove highly informative.

Theoretically, this study has attempted to apply both post-structural gender theory and some of Bourdieu's sociological ideas to understanding the participants' mathematical biographies. Post-structural research on gender and mathematics has considerable explanatory power in terms of, for example, British students' overall low levels of engagement with mathematics, and with the low participation of girls in particular (Boaler et al. 2011). However, I would suggest that its explanatory power is weaker in the case of the significant minority of students who do choose to continue 
with mathematics once it is optional and achieve highly in it, especially in the case of girls. In some cases such students may subvert dominant discourses to suit their needs, as in the case of students with 'geek capital' (Moreau et al. 2010). Alternatively, they may resist the discourses with overt displays of behaviour that bely the implications of their high achievement - for example through gender-normative appearance and 'hyperfemininity' (Francis et al. 2010). In both of these interpretations, high achievement is framed as an act of resistance or subversion of discourses about gender and mathematics, that is, there is a strong focus on identity work. However, for the students I interviewed, images of mathematicians as socially inept, white, middle-class men seemed less relevant. The discourses had been disarmed, deflated. Given that discourses did not appear to be the central influence in my participants' mathematical identity formation, I had to look elsewhere for clues about what enabled the students' remarkable levels of success in mathematics.

The students in this study were exceptional, perhaps exceptionally insulated from negative discourses about mathematics, and as a result their stories demonstrate that the power that discourses have over individuals may vary with social context. This simultaneous use of post-structural or 'discourse' theory and theories of social structure has the potential to underpin more nuanced understandings of the roles of gender and social background in producing inequalities in mathematics education.

\section{Conclusion: towards theoretical reflexivity}

This analysis has broader implications for scholars of gender and education, a community that has a highly coherent substantive focus alongside a highly eclectic mix of theoretical and disciplinary orientations. Even in a narrower sub-field such as gender and mathematics education, the scholarly conversation is happening in a range of academic languages, with varying degrees of mutual intelligibility. As we have these 
conversations, girls with good mathematics results continue to drop the subject because they perceive it as too difficult, or not for them (e.g., Brown et al. 2008). In this article I have suggested that the best way of interpreting data can sometimes be to pick up new theoretical tools part way through the job. Another way to describe this process of 'picking up new tools' is theoretical reflexivity. The value of biographical reflexivity (what is my personal standpoint in relation to this research?) and methodological reflexivity (are these the best methods for addressing my research questions?) is arguably well-established in the gender and education community. However, I would suggest that it is common practice to treat our theoretical approach as a starting point rather than something we need to reflect upon, justify, and possibly modify for any given process of data interpretation.

To switch from the metaphor of theory as tool to theory as a place to stand when seeing and describing the object of our research, this article has outlined a process of saying as a researcher 'I can't see it very well from here (a post-structural standpoint), maybe I should move (to a Bourdieusian standpoint) so that I can get a better view'. A limitation of my analysis is that it only examines the data from two standpoints, and others perspectives may have revealed more illuminating interpretations of my participants' narratives. The ability to practise theoretical reflexivity or 'stand in different places' is of course limited by our knowledge of different theoretical approaches, and part of the purpose of the development of gender theory is the creation of new places to stand in empirical research. Gender and Education, as a journal with a highly multi-disciplinary community of contributors and readers, is well positioned to become a forum in which theoretical reflexivity can flourish. At its best it enables readers to engage with new theoretical perspectives applied by scholars in other disciplines to topics (such as gender inequalities in mathematics education) of 
substantive interest. This process, however, is not automatic, and relies on us either explaining the academic language associated with our standpoints, or attempting to use more accessible language without diluting our meaning.

This article has charted my process of data analysis and interpretation chronologically - an emphasis on discourse followed by an emphasis on peer groups. The purpose of such a structure was to document one attempt to approach data reflexively in terms of the theoretical frameworks employed. I am suggesting neither that theoretical reflexivity is a new concept nor that the current study exemplifies it in any uniquely compelling way. Indeed, it would be easy to list empirical studies that reflexively use diverse theoretical approaches, either in combination (for example, Reay 2002) or in parallel (for example, Cooper 1998), as well as studies that are explicit in their defence of employing a single over-arching theoretical framework (for example, Mendick 2006). The case I have argued here is that there is much to be gained from questioning the theories we use, and that theoretical reflexivity is one way in which we could think about such questioning.

\footnotetext{
${ }^{1}$ Boffin, an English colloquial term, and geek, both "evoke a combination of high academic application and ability, unfashionability/'squareness' and lack of 'peer-oriented' social skills.” (Mendick \& Francis 2012, p. 22)

${ }^{2}$ Cathy Smith (2010. p. 100) clarifies that, in England and Wales "Further Mathematics' extends the 'Mathematics' A-level curriculum by developing content in algebra and calculus, and including a wider range of applications. Since the 1960s, it has played a narrow but significant role in identifying academic achievers and preparing them for mathematically demanding degrees."
} 


\section{References}

Bernstein, B. 2000. Pedagogy, symbolic control and identity: Theory, research and critique (revised edition). Oxford: Rowman \& Littlefield Publishers.

Bhaskar, R. 1975. A realist theory of science. Leeds: Leeds Books.

Bibby, T. 2002. Shame: An emotional response to doing mathematics as an adult and a teacher. British Educational Research Journal 28, no 5: 705-21.

Boaler, J., L. Altendorff and G. Kent. 2011. Mathematics and science inequalities in the united kingdom: When elitism, sexism and culture collide. Oxford Review of Education 37, no 4: 457-84.

Bourdieu, P. 1984. Distinction: A social critique of the judgement of taste. London: Routledge.

Bourdieu, P. 1991. Language and symbolic power. Cambridge, MA: Harvard University Press.

Brooks, R. and J.L. Waters. 2011. Student mobilities, migration and the internationalization of higher education. Basingstoke: Palgrave Macmillan. http://search.lib.cam.ac.uk/?itemid=|cambrdgedb $\mid 5158587$

Brown, M., P. Brown and T. Bibby. 2008. "I would rather die": Reasons given by 16year-olds for not continuing their study of mathematics. Research in Mathematics Education 10, no 1: 3-18.

Butler, J. 1990. Gender trouble: Feminism and the subversion of identity. New York: Routledge.

Cann, R. 2009. Girls' participation in post-16 mathematics: A view from pupils in wales. Gender and Education 21, no 6: 651-69.

Cooper, B. 1998. Using bernstein and bourdieu to understand children's difficulties with "realistic" mathematics testing: An exploratory study. International Journal of Qualitative Studies in Education 11, no 4: 511-32.

Cooper, B. and M. Dunne. 2000. Assessing children's mathematical knowledge: Social class, sex and problem-solving. Buckingham: Open University Press.

Creswell, J.W. 2007. Qualitative inquiry and research design: Choosing among five approaches. 2nd ed. Thousand Oaks, CA: Sage.

Davies, B. 2002. Shards of glass : Children reading and writing beyond gendered identities Language \& social processes. Rev. ed. Cresskill, NJ: Hampton Press. http://search.lib.cam.ac.uk/?itemid=|depfacaedb|433981

De Freitas, E. 2008. Mathematics and its other: (dis)locating the feminine. Gender and Education 20, no 3: 281-90.

Dowling, P. 1996. A sociological analysis of school mathematics texts. Educational Studies in Mathematics 31, no 4: 389-415.

Epstein, D., H. Mendick and M.-P. Moreau. 2010. Imagining the mathematician: Young people talking about popular representations of maths. Discourse: Studies in the Cultural Politics of Education 31, no 1: 45-60.

Foucault, M. 1972. The archaeology of knowledge. London: Routledge.

Francis, B., C. Skelton and B. Read. 2010. The simultaneous production of educational achievement and popularity: How do some pupils accomplish it? British Educational Research Journal 36, no 2: 317-40.

Gates, P. and R. Jorgensen. 2009. Foregrounding social justice in mathematics teacher education. Journal of Mathematics Teacher Education 12, no 3: 161-70.

Gillies, V. 2006. Working class mothers and school life: Exploring the role of emotional capital. Gender and Education 18, no 3: 281-93. 
Ingram, N. 2009. Working-class boys, educational success and the misrecognition of working-class culture. British Journal of Sociology of Education 30, no 4: 42134.

Ingram, N. 2011. Within school and beyond the gate: The complexities of being educationally successful and working class. Sociology 45, no 2: 287-302.

Mendick, H. 2006. Masculinities in mathematics. Maidenhead: Open University Press.

Mendick, H. and B. Francis. 2012. Boffin and geek identities: Abject or privileged? Gender and Education 24, no 1: 15-24.

Moreau, M.-P., H. Mendick and D. Epstein. 2010. Constructions of mathematicians in popular culture and learners' narratives: A study of mathematical and nonmathematical subjectivities. Cambridge Journal of Education 40, no 1: 25-38.

Noyes, A. 2006. School transfer and the diffraction of learning trajectories. Research Papers in Education 21, no 1: 43-62.

Palmer, A. 2009. 'I'm not a "maths-person"!' reconstituting mathematical subjectivities in aesthetic teaching practices. Gender and Education 21, no 4: 387-404.

Reay, D. 1998. Ed. Mahony, P and Zmroczek, C. Class work: Mothers' involvement in their children's primary schooling Women \& social class. London: RoutledgeFalmer.

Reay, D. 2002. Shaun's story: Troubling discourses of white working-class masculinities. Gender and Education 14, no 3: 221-34.

Reay, D. 2004. 'Mostly roughs and toughs': Social class, race and representation in inner city schooling. Sociology 38, no 5: 1005-23.

Reay, D. 2006. "I'm not seen as one of the clever children": Consulting primary school pupils about the social conditions of learning. Educational Review 58, no 2: 17181.

Reay, D. 2015. Habitus and the psychosocial: Bourdieu with feelings. Cambridge Journal of Education 45, no 1: 9-23.

Reay, D., G. Crozier and J. Clayton. 2009. 'Fitting in' or 'standing out': Working-class students in uk higher education. British Educational Research Journal 32, no 1: $1-19$.

Sayer, A. 2000. Realism and social science. London: Sage.

Skeggs, B. 2004. Class, self, culture. London: Routledge.

Smith, C. 2010. Choosing more mathematics: Happiness through work? Research in Mathematics Education 12, no 2: 99-115.

Solomon, Y., D. Lawson and T. Croft. 2011. Dealing with 'fragile identities': Resistance and refiguring in women mathematics students. Gender and Education 23, no 5: 565-83.

Spencer, S.J., C.M. Steele and D.M. Quinn. 1999. Stereotype threat and women's math performance. Journal of Experimental Social Psychology 35, no 1: 4-28.

Walkerdine, V. 1998. Counting girls out: Girls and mathematics. new ed. London: Falmer Press.

Zevenbergen, R. 2005. The construction of a mathematical habitus: Implications of ability grouping in the middle years. Journal of Curriculum Studies 37, no 5: 607-19. 